\title{
Male breast enlargment after automated implantable cardioverter-defibrillator placement
}

\author{
Anisha Valluri, BS ${ }^{1}$ and Lynne J. Goebel, MD'
}

ABSTRACT

Placement of implantable cardioverter-defibrillators (ICDs) is increasing in frequency due to their indication for the prevention of sudden cardiac death in patients prone to life-threatening arrhythmias. Primary care physicians should be aware of the possible complications so they can treat their patients appropriately. This article describes a rare case of chronic unilateral breast enlargement after the placement of an ICD in a male patient with Tetralogy of Fallot.

\section{KEYWORDS}

Tetralogy of Fallot, automated implantable cardioverter-defibrillator, young adult, male, breast enlargement, pacemaker complication

\section{INTRODUCTION}

There are many causes of male breast enlargement. Male breast cancer accounts for less than $1 \%$ of breast cancers. ${ }^{1}$ Benign processes include sebaceous cysts, lipomas, hematomas, excess adipose tissue, and gynecomastia. ${ }^{2}$ Gynecomastia, the most common cause of male breast enlargement, is defined as the benign enlargement of glandular tissue. caused by the effects of an elevated estrogen to androgen ratio. ${ }^{2}$ Physiological gynecomastia occurs during three life stages: the neonatal period, puberty, and over 60 years of age. ${ }^{3}$ Pathological gynecomastia can be caused by a range of conditions such as endocrine dysfunction, tumors, renal failure, cirrhosis, and medication. ${ }^{3}$

latrogenic causes of breast enlargement are less well-documented. To the best of our knowledge, unilateral gynecomastia has not previously been reported as a complication of implantable cardioverter-defibrillator (ICD) placement. Complications arise in about thirty percent of patients who receive ICDs. ${ }^{4}$ We report a young male patient with Tetralogy of Fallot who developed left-sided breast enlargement following ICD placement.

\section{CASE}

The patient is a 29-year-old African American male with a history of Tetralogy of Fallot (TOF) with pulmonary atresia and tricuspid regurgitation, who had multiple surgeries including a Blalock Taussig shunt in 1984, a ventricular septal defect closure in 1986, aortic root homograft conduit replacement in 1988, and pulmonary valve replacement with Carpentier-Edwards heterograft in 1992. His cardiologist prescribed medication after multiple unsuccessful ablation attempts for atrial fibrillation and flutter. In 2010, an ICD was implanted due to syncope related to Infra-Hisian conduction disease. He complained of painless enlargement of his left breast since receiving the ICD. Medications included diltiazem, metoprolol, dabigatran, and dofetilide. He 


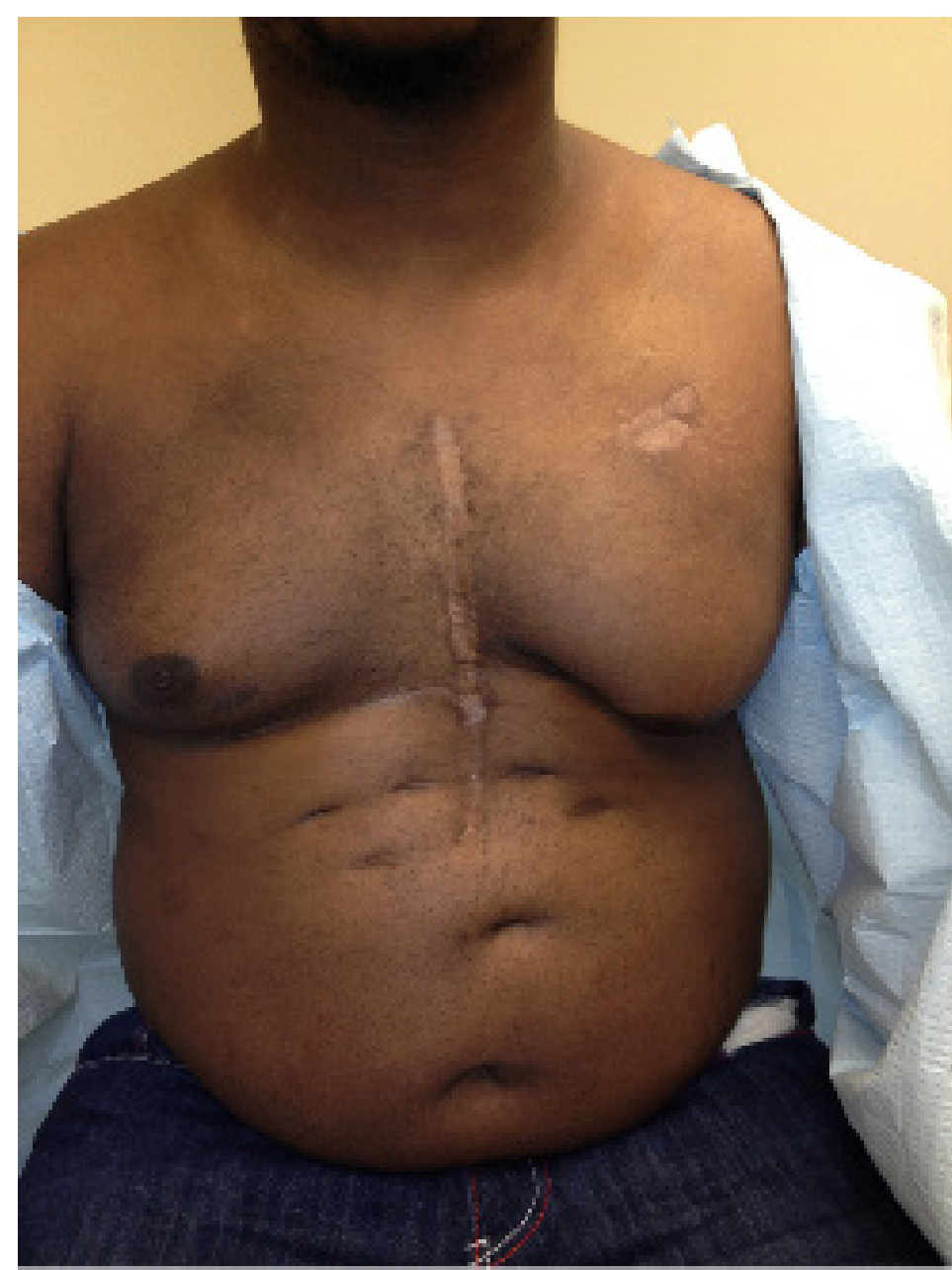

Figure 1. Evidence of left-sided breast enlargement, postICD placement

denied alcohol or drug abuse. He is sexually active with no erectile dysfunction. Record review revealed he was taking sotalol and not diltiazem at the time breast enlargement began. One year prior to our visit, the patient had a CT chest to evaluate the breast enlargement which revealed gynecomastia.

On physical examination, the patient had a blood pressure of $112 / 74 \mathrm{~mm} \mathrm{Hg}$ and a pulse of 86 beats per minute. His BMI was 32. His anterior chest wall revealed well-healed median sternotomy and ICD scars. The left breast was significantly larger than the right breast (Figure 1). There was no tenderness, discrete mass, or nipple discharge. Auscultation revealed a previously noted systolic murmur heard best over the right upper sternal border. His testicular exam was normal.

Bloodwork including prolactin $(7.3 \mathrm{ng} / \mathrm{ml}$ (2.1-17.7 $\mathrm{ng} / \mathrm{ml}))$, testosterone $(433 \mathrm{ng} / \mathrm{dl}$ (348-1197 ng/dl)), and TSH (2.089 mlU/L (0.37-4.42 mlU/L)) was normal. The patient refused an ultrasound and mammogram. The primary care physician contacted the surgeon who placed the ICD, who thought it might be a seroma, and stated he would repair it when the battery needed changing. Four months later, the patient had a malfunctioning right ICD lead replaced. The operative report does not mention a seroma or abnormal location of the ICD outside of the pocket and upon the follow-up exam, the breast enlargement was unchanged. The patient moved to another city. When contacted by phone, he reported that the breast enlargement is unchanged.

\section{DISCUSSION}

To the best of our knowledge, breast enlargement following ICD placement has not previously been reported. The differential diagnosis for new unilateral breast enlargement includes inflammatory breast carcinoma, lymphatic or venous obstruction, mastitis, fat necrosis, hormonal imbalance, and congestive heart failure. ${ }^{5}$ We considered hormonal imbalance in our patient, but he had no symptoms of hormone excess such as pain associated with breast enlargement or erectile dysfunction. Although there is fair quality data that connects diltiazem to gynecomastia, the patient was not taking this when his breast enlargement began. ${ }^{6}$ Our clinical diagnosis is gynecomastia, which is consistent with the appearance on our patient's CT scan. We believe the patient's gynecomastia was caused by obesity but was worsened by concomitant lymphatic obstruction from multiple surgeries. The authors admit we have no direct proof that 
this is the diagnosis; however, we have a CT scan showing gynecomastia, an operative report showing no abnormality with the ICD pocket, and the temporal relationship of breast enlargement to the procedure.

Gynecomastia is more common in elderly men than in younger men and is often related to a clinical cause, including medications, an underlying disease, or an idiopathic condition. ' Classic gynecomastia does not require mammography and is symmetrically placed under the nipple, firm or rubbery upon palpation, and most often bilateral. This is opposed to breast cancer, which is most often a non-symmetrical, unilateral, fixed mass. Our patient did not have the classic lump under the nipple on exam, and while mammography and ultrasound were considered due to the rapid onset, the patient refused this evaluation. Laboratory tests such as testosterone, prolactin, luteinizing hormone, estradiol, human chorionic gonadotropin, thyroid, liver, and kidney function can be performed as part of the evaluation of gynecomastia if there is recent onset breast enlargement and breast tenderness.

Our patient's gynecomastia occurred immediately following the placement of his ICD. The most common ICD-related complication encountered in the TOF population is inappropriate shocks that are not life-threatening. The DAI-T4F National Registry of all TOF subjects implanted with an ICD between 2005 and 2016 showed that $\geq 1$ complication occurred in 40 patients (39\%), including inappropriate shock $(n=26)$, major pocket hematoma $(n=1)$, lead dysfunction $(n=15)$, infection $(n=6)$, reflex sympathetic dystrophy $(n=2)$, and device failure needing reintervention $(n=3) .{ }^{8}$ Our patient also experienced lead dysfunction, which is a known complication; however, unilateral breast enlargement has not previously been reported.

\section{CONCLUSION}

As an increasing number of patients receive ICDs, physicians should be aware of the possible complications to allow for appropriate and timely treatment. We present this case of unilateral breast enlargement following ICD placement to bring awareness to this potential complication, and to discuss the differential and evaluation of this problem.

\section{AUTHOR AFFILIATIONS}

1. Marshall University Joan C. Edwards School of Medicine, Huntington, West Virginia

\section{REFERENCES}

1. Siegel RL, Miller KD, Jemal A. Cancer statistics, 2017. CA Cancer J Clin. 2017 Jan;67(1):7-30.

2. Johnson RE, Murad MH. Gynecomastia: pathophysiology, evaluation, and management. Mayo Clin Proc. 2009;84(11):1010-1015.

3. Swerdloff RS, Ng CM. Gynecomastia: Etiology, Diagnosis, and Treatment. 2019 Jul 7. In: Feingold KR, Anawalt B, Boyce A, Chrousos G, de Herder WW, Dungan K, Grossman A, Hershman JM, Hofland HJ, Kaltsas G, Koch C, Kopp P, Korbonits M, McLachlan R, Morley JE, New M, Purnell J, Singer F, Stratakis CA, Trence DL, Wilson DP, editors. Endotext [Internet]. South Dartmouth (MA): MDText.com, Inc.;2000.

4. Yaminisharif A, Soofizadeh N, Shafiee A, Kazemisaeid $A$, Jalali $A$, and Vasheghani-Farahani A. Generator and lead-related complications of implantable cardioverter defibrillators. Int Cardiovasc Res J. 2014;8(2):66-70.

5. Kwak JY, Kim EK, Chung SY, You JK, Oh KK, Lee $\mathrm{YH}$, Kwon TH, and Jung HK. Unilateral breast edema: spectrum of etiologies and imaging appearances. Yonsei Med J. 2005 Feb 28;46(1):1-7.

6. Deepinder F, Braunstein GD. Drug-induced 
gynecomastia: an evidence-based review. Expert Opin Drug Saf 2012;11(5):779-795.

7. Hines, SL, Tan W, Larson JM, Thompson KM, Jorn HKS, Files JA. Evaluation of breast masses in older men. Geriatrics. 2008;63(6):19-23

8. Bouzeman A, Sharifzadehgan A, Marquie C, Gandjbakhch E, Martins R, Fauchier L, Defaye P, Sellal JM, Mondoly P, Labombarda F, Anselme F, Lellouche N, Thambo JB, Combes N, and Marijon E. Implantable cardiac defibrillator in the setting of tetralogy of fallot: Data from the DAI-T4F National Registry. European Heart Journal, 2017 38(1): ehx504.3874, https://doi.org/10.1093/eurheartj/ehx504.3874 